\title{
DEPRESSION IN PARKINSON'S DISEASE
}

\section{Study of 60 cases}

\author{
Roberto César Pereira do Prado', Egberto Reis Barbosa
}

\begin{abstract}
Depression is very frequent in Parkinson's disease (PD) and largely unrecognized by neurologists, emphasizing the need of an approach to psychiatric symptoms by non psychiatrists in order to ensure an early diagnosis of depression in PD; clinical characteristics and the prevalence rate of depression in PD we re evaluated and the relationship of depression in PD with other variables were determined. Sixty PD subjects, who fulfilled the clinical criteria for primary PD, 56,6\% males, age range from 44 to 85 years old, in different stages of the disease were investigated. All subjects were submitted to the UPDRS-III, V and VI, Clinical Interview Schedule and the Hamilton depression scale. A significant correlation was found between depression and UPDRS-III, V and VI, anxiety andiritability. The frequency of depression in PD in this study was nearly $40 \%$ possessing specific features. Structured interviews and evaluation scales are essential for an accurate diagnosis and proper treatment of depression in PD.
\end{abstract}

KEY WORDS: depression, Parkinson`s disease, neuropsychiatric disorders, diagnosis, comorbidity.

\section{Depressão na doença de Parkinson: estudo de 60 casos}

RESUMO - A depressão é manifestação freqüente na evolução da doença de Parkinson (DP), gerando a necessidade de nova abordagem neuropsiquiátrica por parte dos médicos não psiquiatras, visando o reconhecimento precoce do quadro depressivo na DP. Foram estudadas as características clínicas e freqüência da depressão na DP e correlacionadas com outras variáveis. Sessenta pacientes que preenchiam os critérios clínicos atuais para DP, sendo $56,6 \%$ do sexo masculino (44 a 85 anos), em diferentes estágios clínicos da doença, foram submetidos ás escalas de avaliação para DP (UPDRS-III, V e VI), para transtornos neuropsiquiátricos Entrevista Clínica Estruturada e Escala de Hamilton. Houve associação estatisticamente significante entre depressão e UPDRS-III, V e VI, ansiedade e irritabilidade. A freqüência de depressão, situou-se em torno de $40 \%$ apresentando características próprias. Entrevistas estruturadas e escalas de avaliação são essenciais para o diagnóstico preciso e tratamento adequado do fenômeno depressivo na DP.

PALAVRAS-CHAVE: depressão, doença de Parkinson, manifestações neuro co m p o rtamentais, diagnóstico, comorbidade.

The nonmotor symptoms (e.g., dementia, autonomic dysfunction, and mood disturbances) are rather frequent in Parkinson's disease (PD), being as common as the motor symptoms that are highly characteristic of this disease ${ }^{1,2}$. These manifestations can be the most disturbing and disabling aspects of the disease. Depressive symptoms are particulaly a significant cause of functional impairment for these patients. Depressive symptoms have also been described in other movement disorders such as Huntington disease, basal ganglia idiopathic calcification, Wilson's disease, vascular parkinsonism, progressive supranuclear palsy, neuroakanthocytosis, dystonia, spino-cerebellar degeneration ${ }^{3}$. The as- sessment of comorbid psychiatric symptoms in PD subjects should take into account if symptons are 1) anti-parkinson medication-induced; 2 ) secondary to PD disease phenomena, like depression or anxiety secondary to motor fluctuations; 3 ) combination of disease factors and medication side-effects. The presence of psychiatric symptoms will demand different actions as anti-parkinson medication reduction or addition of a psychoactive drugs. Among several psychiatric symptoms, depression stands out because of its unique features and high prevalence rate in PD.

$D$ e $p$ ression is by far the most common psychatric finding in PD. Prevalence rates span from 4 to

\footnotetext{
'Departamento de Medicina, Universidade Federal de Sergipe, Aracaju SE, Brasil: Professor Adjunto; ${ }^{2}$ Departamento de Neurologia, Universidade de São Paulo, São Paulo, SP, Brasil: Livre Docente
}

Received 1 November 2004, received in final form 6 May 2005. Accepted 10 June 2005.

Dr. Roberto César P. do Prado - Rua Celso Oliva 321/301 - 49020-090 Aracaju SE - Brasil. E-mail: rcprado@infonet.com.br 
$70 \%$ depending on the methodology employed. Data from studies employing the Beck Depression Inventory (BDI) or the Hamilton Rating Depression Scale (HRDS) showed a prevalence rate of $40 \%$, an incidence rate of $1.86 \%$ a year and a cumulative risk of $8.60 \%{ }^{4}$. Depressed PD patients typically present lack of motivation, reduced self-steem, high level of anxiety, pessimism about the future, irrita bility, suicide ideation and rarely suicide atempt and hallucinations and delusions ${ }^{5}$. The diagnosis of depression in PD as well as in other hipokinetic movement disorders is particularly difficult because, perhaps more than any other medical disorder, the symptoms of PD overlap with the symptoms of depression ${ }^{1,6,7}$. Most patients with PD appear depressed to the passive observer. The "masked facies", psychomotor slowing and fatigue of PD give the appearance of depression in euthymic patients ${ }^{8}$. On the other hand, depression in PD is often not recognized by neurologists.

The objective of this study was to assess neuropsychiatric symptoms, specially depression, in a selected group of PD patients.

\section{METHOD}

Sixty consecutive PD subjects were included in this study. There were 34 males $(56.6 \%)$ and 26 females $(43.30 \%)$ and average age was $64.83 \pm 11.64$ years (age range from 44 to 85 years old). The London Brainbank diagnosis criteria was employed for the clinical diagnosis of PD in all patients ${ }^{9}$. All patients were examined at the University Hospital - Federal University of Sergipe Unity of Movement Disorders and were seen from November 1997 through May 2001.

Unified Parkinson's Disease Rating Scale (UPDRS) part III (motor signs), part V (Hoehn and Yahr PD staging scale), part VI (Schwab and England daily activities scale) and the Mini-Mental State test - MMS - were applied to all patients to assess respectively, the degree of clinical parkinsonian symptoms and cognitive status of the studied group ${ }^{10}$.

A three-level stratification was necessary for the MMS scores because the studied population included several patients with minimal educational background or illiterate ${ }^{11,12}$. Three patient groups were created according to educational level: illiterate group, minimal educational level ( $<8$ years of school education) and ele vated educational level ( $>8$ years of school education). Three distinct MMS scores corresponding to the patient $g$ rouping described above were fixed: 18 points for the illiterate group, 21 points minimal educational level and 24 points for elevated educational level as suggested by some authors ${ }^{12}$.

The Portuguese version of the Clinical Interview Schedule (CIS-R) was applied to each individual patient by the first author to determine the presence of psychiatric symptoms ${ }^{13}$. Specific CIS-R questions concerning symptoms primarily related to the Parkinson's disease resembling somatic symptoms, body functions, tiredness were excluded as recommended by Botega et al. ${ }^{13}$. Clinical suspicion for depression was achieved in all subjects who scored two or more points in the depression or depressive thoughts.

The Portuguese version of the HAM-D was subsequently applied to all patients bearing a clinical suspicion of depression ${ }^{14}$. The authors adopted the 17-item score range 0 to 50 points HAM-D scale instead of the full 21-item scale. The remaining 4-item list was not included because it assesses findings as diurnal mood variation, delusions, paranoid and obssessive symptoms which not only are uncommon in PD but it does not significant contribute to the overall estimative of the affective disorder. HAM-D scores up to seven points were conside red normal, a score between 7 through 17 points was indicative of mild depression, 18 up to 24 points was considered moderate and above 25 points was considered depression of a severe degree ${ }^{14}$.

A brain CT scan with contrast was obtained for all patients. Those presenting CT scan abnormalities other than volumetric reduction of the brain were excluded from the study.

Statistical analysis - The clinical characteristics and the prevalence rate of depression as well as age, gender, age at disease onset, duration of motor dysfunction, motor dysfunction laterality, PD stage, functional disability, cognitive status were analysed. The Student's t test was employed to compare the average of the quantitative variables between the depressed and non-depressed subjects. The chi-square or Fischer-s tests were applied to the quantitave variables and the odds-ratio between the depressed and non-depressed patients to evaluate more important features. Person's and Spearman's correlation measures were employed to assess the continuous variables. An alpha of $5 \%$ was considered statistically significant for all tests. Descriptive indexes lower than $\mathrm{p}=.05$ were statistically significant. Stata 7.0 version software was employed for the analysis.

\section{RESULTS}

Thirty-four males (56.6\%) and 26 females (43.3\%) were included. Age range was 64.83 (44 to 85 years), disease onset age was 61.31 (41 to 82 ) and disease average duration was 4.42 anos ( 0.16 to 13 ). The relative frequency of neuropsychiatric manifestations is depicted in Figure 1.

Mild depression was recorded in $82.60 \%$ whereas moderate and severe depression rates were $8.69 \%$ as shown in Figure 2.

There was a statistically significant correlation between depression and motor symptoms evaluated by UPDRS part III (chi-square $=6.7685, p=0.009$ 


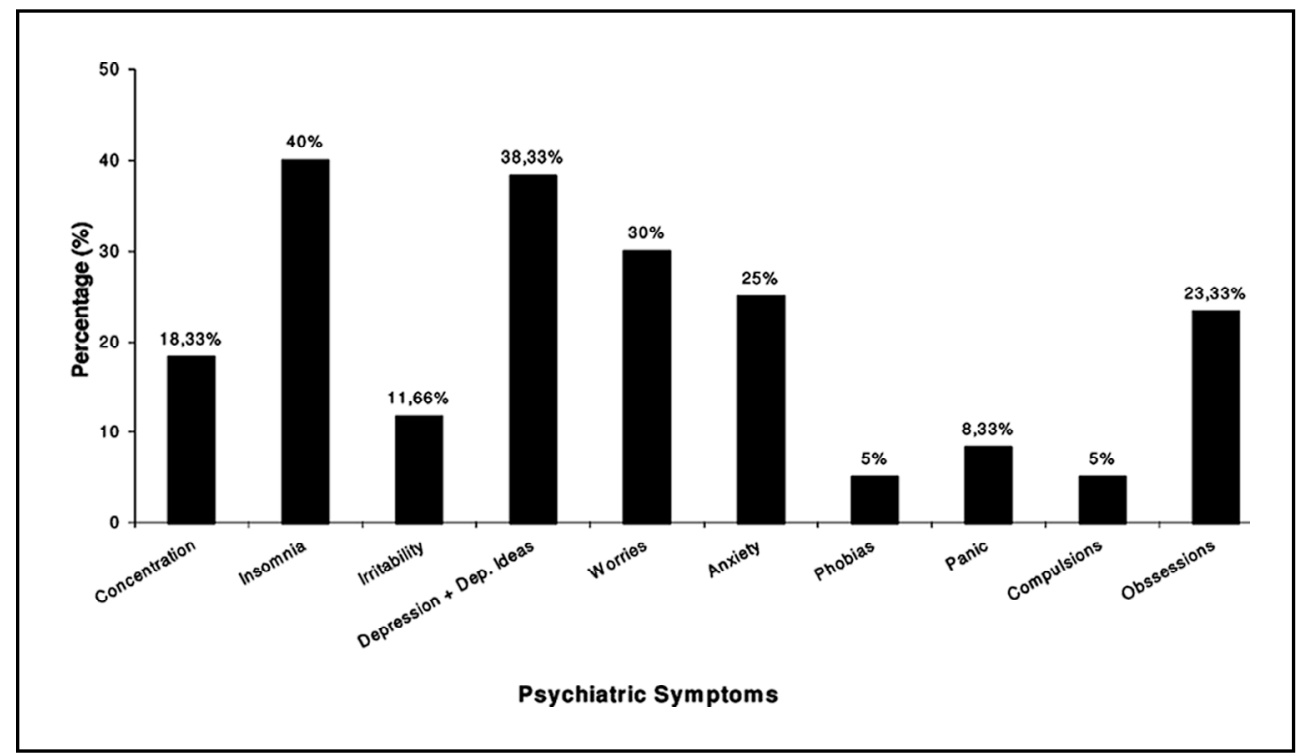

Fig 1. Relative frequency of psychiatric symptoms in PD.

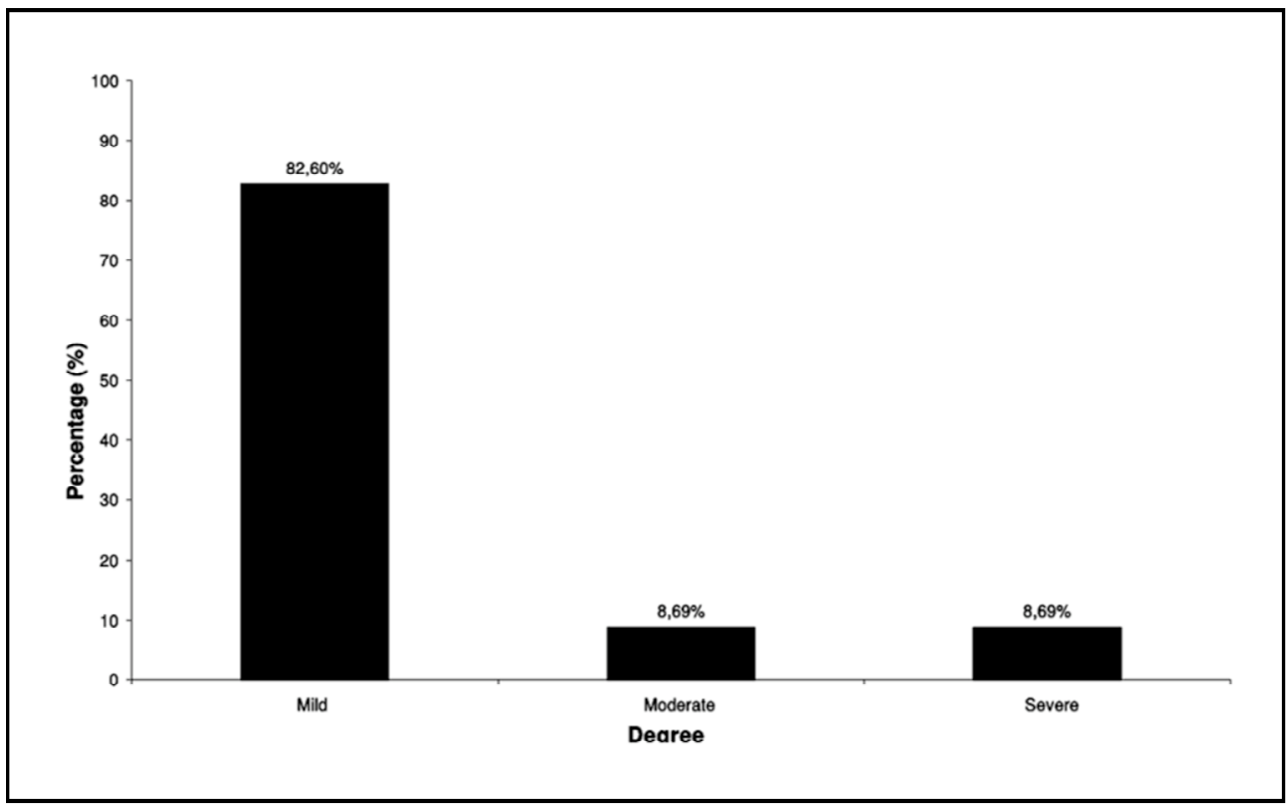

Fig 2. Distribution of the depressed parkinsonian patients according to the degree of depression.

- Table 1); disease staging scored by UPDRS part $\mathrm{V}$ (chi-square=6.3316, $\mathrm{p}=0.012$ - Table 2 ) and for performance at daily activities, assessed by UPDRS part VI (chi-square $=16.4076, \mathrm{p}=<0.001-$ Table 3).

A statistically significant association was found for depression and irritability (chi-square $=8.8187$, $p=0.032$ - Table 4), worrying thoughts (chi-square $=19.1640, p=0.001-$ Table 5 ) and anxiety (chisquare $=19.6005, p=0.001$ ).

\section{DISCUSSION}

The frequency of depression (38.33\%) record- ed in the present investigation is in keeping with the current literature data ${ }^{4,15,16}$. Specific clinical features of the depression in the present investigation were sleep complaints, anxiety, irritability and lack of concentration and interest. However, symptoms like guilty feelings, self-destruction, suicidal thoughts were not recorded in this sample as they usually are in a primary depression population.

An important point in an investigation pertaining to PD and depression concerns the most adequate instruments to assess the affective symptoms. Shulmam et al. ${ }^{17} \mathrm{from}$ the University of Miami have 
Table 1. Number and percentage of depression in relation to UPDRS-III (motor examination), Odds Ratio (OR) with confidence intervals (CI) of $95 \%$.

\begin{tabular}{lcccccccc}
\hline Motor exam & \multicolumn{3}{c}{ no } & \multicolumn{2}{c}{$\begin{array}{c}\text { Depression } \\
\text { yes }\end{array}$} & \multicolumn{3}{c}{ total } \\
(0- 56 points) & $\mathrm{N}$ & $\%$ & $\mathrm{~N}$ & $\%$ & $\mathrm{~N}$ & $\%$ & $\mathrm{OR}$ & $\mathrm{Cl}(95 \%)$ \\
\hline $2-18$ & 27 & 75.00 & 09 & 25.00 & 36 & 100 & $1^{*}$ & - \\
$19-46$ & 10 & 41.67 & 14 & 58.33 & 24 & 100 & 4.20 & $1.28-13.75$ \\
Total & 37 & 61.67 & 23 & 38.33 & 60 & 100 & & \\
\hline
\end{tabular}

*reference: chi-square $=6.7685, p=0.009$.

Table 2. Number and percentage of depression in relation. to UPDRS-V (Hoehn-Yahr), Odds Ratio (OR) with confidence intervals (CI) of $95 \%$.

\begin{tabular}{lcccccccc}
\hline Hoehn-Yahr & \multicolumn{3}{c}{ no } & \multicolumn{2}{c}{ Depression } \\
yes & \multicolumn{2}{c}{ yes } & \multicolumn{2}{c}{ total } \\
$(0-5)$ & $\mathrm{N}$ & $\%$ & $\mathrm{~N}$ & $\%$ & $\mathrm{~N}$ & $\%$ & $\mathrm{OR}$ & $\mathrm{Cl}(95 \%)$ \\
\hline $1-2.5$ & 28 & 73.68 & 10 & 26.32 & 38 & 100 & $1^{*}$ & $-1.23-13.28$ \\
$3-5$ & 9 & 40.91 & 13 & 59.09 & 22 & 100 & 4.04 & 1.28 \\
Total & 37 & 61.67 & 23 & 38.33 & 60 & 100 & & \\
\hline
\end{tabular}

${ }^{*}$ reference: chi-square $=6.3316, p=0.012$.

Table 3. Number and percentage of depression in relation to UPDRS-VI (Schwab-England), Odds Ratio (OR) with confidence inter vals (CI) of $95 \%$.

\begin{tabular}{lcccccccr}
\hline Schwab-England & \multicolumn{2}{c}{ no } & \multicolumn{2}{c}{ Depression } \\
yes & \multicolumn{2}{c}{ yes } & \multicolumn{2}{c}{ total } \\
$(100 \%-0 \%)$ & $\mathrm{N}$ & $\%$ & $\mathrm{~N}$ & $\%$ & $\mathrm{~N}$ & $\%$ & $\mathrm{OR}$ & $\mathrm{Cl}(95 \%)$ \\
\hline $80-100$ & 29 & 82.86 & 6 & 17.14 & 35 & 100 & $1 *$ & - \\
$50-70$ & 4 & 26.67 & 11 & 73.33 & 15 & 100 & 13.29 & $2.34-75.47$ \\
$20-50$ & 4 & 40.00 & 6 & 60.00 & 10 & 100 & 7.25 & $1.32-39.77$ \\
Total & 37 & 61.67 & 23 & 38.33 & 60 & 100 & \\
\hline
\end{tabular}

*reference: chi-square $=16.4076, \mathrm{p}<0.001$.

Table 4. Relation between depression and irritability accord ing to punctuation in CIS-R.

\begin{tabular}{lcccccc}
\hline & \multicolumn{2}{c}{ no } & \multicolumn{2}{c}{ Depression } & \multicolumn{2}{c}{ total } \\
Irritability & $\mathrm{N}$ & $\%$ & $\mathrm{~N}$ & $\%$ & $\mathrm{~N}$ & $\%$ \\
\hline 0 & 30 & 71.43 & 12 & 28.57 & 42 & 100 \\
1 & 6 & 54.55 & 5 & 45.45 & 11 & 100 \\
2 & 1 & 20.00 & 4 & 80.00 & 5 & 100 \\
3 & 0 & 0 & 2 & 100 & 2 & 100 \\
total & 37 & 61.67 & 23 & 38.33 & 60 & 100 \\
\hline * reference, chi-square $=8.8187, \mathrm{p}=0.032$. & &
\end{tabular}

assessed the local staff neurologists accuracy rate of the diagnosis of depression and other psychiatric symptoms in PD patients. Clinical impression based on a routine consultation was compared with specific data obtained from specific clinical scales for dep ression, and other psychiatric symptoms. Clinical assessment accuracy was 35\% for depression.

The overlap of motor symptoms as bradikynesia and psychomotor retardation poses as a real challenge for the diagnosis of affective disorders in PD. For this reason, the authors elected the CIS-R
Table 5. Relation between depression and worries according to punctuation in CIS-R.

\begin{tabular}{lcccccc}
\hline & \multicolumn{2}{c}{ no } & \multicolumn{2}{c}{ Depression } & \multicolumn{2}{c}{ yes } \\
Worries & $\mathrm{N}$ & $\%$ & $\mathrm{~N}$ & $\%$ & $\mathrm{~N}$ & $\%$ \\
\hline 0 & 29 & 80.56 & 7 & 19.44 & 36 & 100 \\
1 & 3 & 50.00 & 3 & 50.00 & 6 & 100 \\
2 & 1 & 20.00 & 4 & 80.00 & 5 & 100 \\
3 & 4 & 57.14 & 3 & 42.86 & 7 & 100 \\
4 & 0 & 0 & 2 & 100 & 2 & 100 \\
total & 37 & 61.67 & 23 & 38.33 & 60 & 100 \\
\hline
\end{tabular}

*reference, chi-square $=19.1640, p=0.001$.

structured interview, an easily applied instrument, usefull to assess the neuropsychiatric symptoms. Additionally, the CIS-R yields a high detection rate of psychiatric symptoms whereas the HAM-D was meant to measure the severity degree of depressive symptoms in this PD population. The combined use of both research instruments minimized the rate of misdiagnosis of psychiatric symptoms by nonpsychiatrists. The newly edit version of the CIS-R can be easiliy applied by other health-related professionals removing thus the time and economic 
b u rden of requiring a trained psychiatrist for this task. As mentioned earlier, specific questions concerning symptoms primarily related to PD itself resembling somatic symptoms, body functions, tiredness were intentionally excluded from the CIS-R as recommended by Botega et al. ${ }^{13}$ to avoid increased scores due to PD-related pseudo-psychiatric manifestations. The importance of some specific questions was present in five PD subjects bearing a typical facial mask and severe motor slowness. These subjects were classified as belonging to stage 4 and 5 according to the Hoehn e Yahr modified scale. These subjects displayed convincing depressed features but they did not score for depression or depressive thoughts in the CIS-R.

The two most common behavioral changes found in Aarsland's series was depression (38\%) and hallucinations (27\%) whereas the least common behavioral changes were euphoria and disinhibition ${ }^{15}$. Aarsland's patient series depression rate is similar to the present study's depression rate ${ }^{15}$. Psychiatric manifestations were by far more common in PD subjects living in retirement homes as o $p$ posed to subjects living at home with family members. In conclusion, the authors emphasized the relevance of psychiatric manifestations in PD as well as the need of clinical neurologists to improve their skill to evaluate the presence and degree of cognitive and psychiatric symptoms in PD patients ${ }^{15}$. Di Giovanni et al. ${ }^{18}$ study with 160 PD HAM-D scale respondents showed that the most common depressive clinical manifestations in that sample were apathy, asthenia and passive negativism. These manifestations are fairly typical of mild depression. Other authors ${ }^{6,19-21}$ report a $50 \%$ rate for depression of a severe degree and a $50 \%$ rate for both mild de$p$ ression and dysthimia. The explanation for these different findings are: firstly the majority of the patients in the present investigation were in the initial stages of the disease (disease average duration of less than 5 years); secondly all subjects were on antiparkinsonian medication (a likely effect of the antiparkinsonian drugs on the patient's'mood can not be ruled out at this time) and some subjects were already on antidepressants or anxiolytics.

Patient's age, disease age onset, disease duration were not statistically significant for affective symptoms in the present series. These findings are in keeping with other literature data, despite Santamaria et al. ${ }^{22}$ and Starkstein et al. ${ }^{23}$ studies showed that depressive symptoms have a tendency to affect patients with earlier disease onset.
The present study revealed no statistically significant correlation between depression and gender. This was also reported by Ehmann et al ${ }^{19}$. However, Warburton ${ }^{24}$ found a female predominance for depressive symptoms in a group of 140 PD patients selected for thalatomy and 140 controls.

The re was no statistically significant correlation between the cognitive changes assessed by the MMS and the depression ratings. One should bear in mind that the MMSE is just a screening test and that mild depression rates predominated in the present series of patients, whereas other investigators as Starkstein et al. ${ }^{25}$ showed a remarkable intellectual deterioration in the severely depressed patients. These authors even proposed two distinct forms of PD, one with rapidly progressive cognitive changes and severe depression and the second type with a slowly cognitive decline without $\mathrm{d}$ e $\mathrm{p}$ ression. The relation between depression and $P D$, yet controversial, presents two clinically relevant points according to the authors ${ }^{25}$. Firstly, the treatment for depression bears the potential to arrest the cognitive decline and secondly, the life expectancy of the PD patients with cognitive decline becomes significantly shorter.

Concerning the correlation between motor dysfunction laterality and depression no statistically significant results were found in this series, as determined likewise by Aarsland et al. ${ }^{15}$. Nonetheless, Direnfeld et al. ${ }^{26}$ data showed that patients with predominance of motor symptoms on the right (corresponding to left side of the brain dysfunction) p resented higher Beck depression inventory scores as opposed to individuals with bilateral motor dysfunction or individuals with left-side predominant motor symptoms. Starkstein et al. ${ }^{27}$ findings also indicate a relationship between elevated depression scores and right side motor dysfunction.

The severity degree of the motor dysfunction assessed by the UPDRS part III and V and depression was statistically significant in the present series. In other words, the more severe the motor impairment was, the more elevated the scores for depressive symptoms. However, this finding does not achieve support in investigations published by other authors ${ }^{19,22,27}$ in which this relation was not observed. Likewise, the correlation between depression and daily activities scale measured with UPDRS - VI was statistically significant. Kostic et al. ${ }^{28}$ results are in keeping with the findings mentioned above despite these authors employed a diffe rent scale to evalu- 
ate daily activities. The authors showed an association between depression and anxiety, as 12 patients from the fifteen that presented a CIS-R score for anxiety $(\geq 2)$, also presented significant scores for depression and/or depressive ideas. Menza et al. ${ }^{29}$ reported that 12 from 42 patients of a PD population sample fulfilled the criteria for anxiety and in this subg roup 11 patients were also depressed.

The association between depression and irritability, depression and worrying thoughts was a significant one in the present series. Out of 18 subjetcts who scored $\geq 2$ in the CIS-R for worrying thoughts, 13 also presented a significant score $\geq 2$ for depression.

This study points at some directions in terms of an ethiopathgenesis for the listed psychiatric changes. The notion of a reactive depression is supported by the correlation between motor changes documented by the UPDRS (parts III, V, VI) and depressive scores. However, the lack of a statistically significant correlation between the subject's age, disease duration and previous history of depression all point in favor towards the hypothesis that the depression in PD is related to the CNS chemical imbalance. We would like to stress that the ethiopathogenesis of psychiatric symptoms in PD is a ve ry complex issue and new studies should be carried out for a better understanding of this topic.

We concluded that: a) the CIS-R (Clinical Interview Schedule - CIS-R) is an usefull clinical instrument that can be applied by non-psychiatrists in the determination of neuro-psychiatric changes; $b$ ) the depression rate found by the authors equivalent to $38.33 \%$ is in keeping with others literature data; C) the depressive syndrome found in this group of PD patients showed somewhat specific characteristics as: sleep complaints, anxiety, lack of concentration, worrying thoughts, iritablility, panic symptoms; no guilty feelings, self-punishment, delusions or suicide were observed in the patients studied; $d$ ) statistically significant correlations between depression and the blocks III (motor examination), $\mathrm{V}$ (Hoehn e Yahr modified scale) and VI (Schwab e England scale) of the UPDRS were observed; e) statistically significant correlation between depression and irritability was found ${ }^{30}$.

\section{REFERENCES}

1. Koller WC, Silver DE, Lieberman A. An algorithm for the management of Parkinson's disease. Neurology 1994;44(Suppl 10):S1-S52.

2. Popovska A, Petrova V, Tanovska N, Petrov I, Vaskov T. Neuropsycological aspects in patients with Parkinson's disease. Mov Disord 1997;12(Suppl 1):S127.
3. Swanberg MM, Foti DJ, Cummings JL. Neurobehavioral aspects of movement disorders. In Watts RL, Koller WC (eds). Movement disorders: neurologic principles and practice. New York: McGraw-Hill, 2004;17-29.

4. Dooneief G, Mirabello E, Bell K, Marder K, Stern Y, Mayeux R. An estimate of the incidence of depression in idiopathic Parkinson's disease. Arch Neurol 1992;49:305-307.

5. Kostic VS. Psychiatric manifestations of Parkinson's disease. Education program syllabus, Movement Disorder Society, 5th international congress of Parkinson's disease and movement disorders. New York, 1998:10-14.

6. Mayeux R, Williams JBW. Assessment of depression in Parkinson's disease. In: Clifford Rose F (ed). Parkinson's disease and the problems of clinical trials. London: Smith-Gordon Nishimura 1992:43-49.

7. Poewe W, Luginger E. Depression in Parkinson's disease. Neurology 1999;52(Suppl 3):S2-S6.

8. Mayberg HS, Solomon DH. Depression in Parkinson's disease: biochemical and organic viewpoint. Adv Neurol 1995;65:49-60.

9. Hughes AJ, Daniel SE, Kilford L, Lees AJ. Accuracy of clinical diagnosis of idiopathic Parkinson's disease: a clinical pathological study of 100 cases. J Neurol Neurosurg Psychiatry 1992;55:181-184.

10. Folstein MF, Folstein SE, McHugh PR. "Mini-mental state": a practical method for grading the mental state of patients for the clinician. J Psychiatr Res 1975;12:189-198.

11. Bertolucci PHF, Brucki SMD, Campacci SR, Juliano Y. O mini-exame do estado mental em uma população geral - impacto da escolaridade. Arq Neuropsiquiatr 1994;2:1-7.

12. Katzman R, Zhang M, Qu OY, et al. A Chinese version of the mini-mental state examination: impact of illiteracy in a Shanghai dementia survey. J Clin Epidemiol 1988;41:971-978.

13. Botega NJ, Zomignani MA, Garcia C Jr, Bio MR, Pereira WAB. Morbidade psiquiátrica no hospital geral: utilização da edição revisada da "Clinical Interview Schedule - CIS-R". Revista ABP - APAL 1994;16:57-62.

14. Moreno RA, Moreno DH. Escalas de avaliação para depressão de Hamilton (HAM-D) e Montgomery - Asberg (MADRS). In Gorenstein C, Andrade LHSG, Zuardi AW (eds). Escalas de avaliação clínica em psiquiatria e psicofarmacologia. São Paulo: Lemos 2000;71-87.

15. Aarsland D, Larsen JP, Lim NG, et al. Range of neuropsychiatric disturbances in patients with Parkinson's disease. J Neurol Neurosurgery Psychiatry 1999;67:492-496.

16. Shulman LM, Taback RL, Bean J, Weiner WJ. Comorbidity of the nonmotor symptoms of Parkinson's disease. Mov Disord 2001;16:507-510.

17. Shulman LM, Taback RL, Singer C, Weiner WJ. The diagnostic accuracy of neurologists for anxiety, depression, fatigue and sleep disorders in Parkinson's disease. Mov Disord 1997;12(Suppl 1):S127.

18. Di Giovanni M, Lia C, Corso G. D'Alessandro G, Bottacchi E. Depression in Parkinson's disease: our experience. Mov Disord 1998;13(Suppl 2):S89.

19. Ehmann TS, Beninger RJ, Gawel MJ, Riopelle RJ. Depressive symptoms in Parkinson's disease: a comparison with disabled control subjects. J Geriatr Psychiatry Neurol 1990;2:3-9.

20. Cummings JL. Depression and Parkinson's disease: a review. Am J Psychiatry 1992;149:443-454.

21. Djaldetti R, Melamed E. Neurobehavioral abnormalities in Parkinson's disease. In Watts RL, Koller WC (eds). Movement disorders: neurologic principles and practice. New York: McGraw-Hill, 2004:319-324.

22. Santamaria J, Tolosa E, Valles A. Parkinson's disease with depression: a possible subgroup of idiopathic parkinsonism. Neurology 1986;36: 1130-1133.

23. Starkstein SE, Berthier ML, Bolduc PL, Preziosi TJ, Robinson RG. Depression in patients with early versus late onset of Parkinson's disease. Neurology 1989;39:1441-1445.

24. Warburton JW. Depressive symptoms in Parkinson patients referred for thalamotomy. J Neurol Neurosurg Psychiatry 1967;30:368-370.

25. Starkstein SE, Bolduc PL, Mayberg HS, Preziosi TJ, Robinson RG. Cognitive impairments and depression in Parkinson's disease: a follow-up study. J Neurol Neurosurg Psychiatry 1990;53:597-602.

26. Direnfeld LK, Albert ML, Volicer L, Langlais PJ, Marquis J, Kaplan E. Parkinson's disease: the possible relationship of laterality to dementia and neurochemical findings. Arch Neurol 1984;41:935-941.

27. Starkstein SE, Preziosi TJ, Bolduc PL, Robinson RG. Depression in Parkinson's disease. J Nerv Ment Dis 1990;178:27-31.

28. Kostic VS, Filipovic SR, Lecic D, Momcilovic D, Sokic D, Sternic N. Ef fect of age at onset on frequency of depression in Parkinson's disease. J Neurol Neurosurg Psychiatry 1994;57:1265-1267.

29. Menza MA, Robertson-Hoffman DE, Bonapace AS. Parkinson's disease and anxiety: comorbidity with depression. Biol Psych 1993;34:465-470.

30. Prado RCP. Depression in Parkinson's disease: study of 60 cases (abstr). Arq Neuropsiquiatr 2002;60:1049. 